\title{
Design and Development of a Versatile and Intelligent Home Security System
}

\author{
Md. Khalid Hossain Jewel ${ }^{\text {a }}$, Md. Niaz Mostakim ${ }^{\text {a }}$, M. K. Rahman ${ }^{\text {a }}$ Md. Shahjahan Ali a, \\ Sheikh Dobir Hossain ${ }^{b}$, Md. Khalid Hossain ${ }^{c}$, Himangshu Kumar Ghosh ${ }^{\mathrm{c}}$ \\ ${ }^{a}$ Dept. of Applied Physics, Electronics \& Communication Engineering, Islamic University, Bangladesh \\ ${ }^{b}$ Dept. of Physics, Jessore University of Science and Technology, Jessore-7408, Bangladesh \\ ${ }^{c}$ Institute of Electronics, Atomic Energy Research Establishment, Savar, Dhaka-1349, Bangladesh
}

\begin{abstract}
This paper deals with the designing and implementation of microcontroller based security system to alert when unauthorized persons try to enter in a home. The first phase of security was implemented using a GSM module to send alert message (SMS). To make the system robust additional layers of security has been incorporated by including security devices such as android based door password, manual keyboard to open the door, PIR motion to detect unauthorized person in the home, rotating ultrasonic sensor by servo motor to active the camera to capture image and RF transceiver to produce voice signal to alert people outside the home. The system's main hardware was designed by Arduino based microcontroller ATmega328. Arduino ISP was used for system designing and Arduino serial monitor is used to test the GSM module. The implemented system was seen to perform well.
\end{abstract}

Index Terms: Intelligence, Security, GSM, Bluetooth, Sensor.

(C) 2017 Published by MECS Publisher. Selection and/or peer review under responsibility of the Research Association of Modern Education and Computer Science

\section{Introduction}

Developing Home security has been a concern for all people living in cities worldwide. Home security systems are for automating, improving security, safety, communication, comfort and energy saving. A smart home system is built with different types of sensors to provide insinuate and precise monitoring [1]. In these days, home security has become an important issue due to high rate of crimes. In the beginning, the security system was quite basic and offered simpler facilities. But in the present days many other facilities are included in the system to make the city-homes more comfortable, intelligent and secure [2,3]. In this work a robust microcontroller based security system was implemented for smart home applications.

* Corresponding author

E-mail address: khalid.baec@yahoo.com 
The rest of the paper has been designed as follows- section-2 related work, section-3 proposed system, section-4 system designing, section-5 hardware, section-5 software simulation circuit, section-6 result and discussion and section-7 conclusions.

\section{Related Work}

Many researchers designed and implemented various types of home security system based on sensor contacts such as finger print and palm print scanner [4] .GSM based security system is also available with them [5]. The range depends on the number of controlling system such as computer or microcontroller with varying automation. Home security system is covered for comfortable security and efficient energy [6]. Many researchers suggested and proposed a number of home security at different techniques based on GSM, GPRS, and Internet technology. R.Hossain et al. has proposed and implemented Global system for mobile communication (GSM) based home security by ATMEGA16 microcontroller with mobile interfacing [7]. F. Shawki et al. and O. Eseosa et al. has proposed a system for smart home with security system based on PIC18F452 microcontroller with GSM technology [8,9]. Additional facilities have been added on this system like temperature sensor, Smoke sensor, Fire sensor, Gas sensor etc. S. Budijono et al. has proposed and implemented home security with short message service (SMS) [10]. This system is maintained or activates and deactivates using SMS through GSM module, Atmega328 and mobile device. Remote monitoring based system has been implemented by N. Agarwal et al. to identify difference LED light intensity captured by photo diode reflected from the finger [11]. Designing and implementing a home security system using 802.15.4 standard known as Zigbee has been proposed by N. Hashim et al. [12]. Motion sensor and magnetic door sensor to give high security are added by them .An online based home security system against intruder and fire and smoke has been implemented by P. S. Bangare et al. [13]. GSM and GPS based intelligent security system to give information of the sensor condition to desired number and find the location to nearest fire station and police station. This system is proposed by Nandeesh G S et al. [14].

\section{Proposed System}

In this work emphasis was given to design a robust system compared to the published reports [15-18], where PIC microcontroller and AT mega serial microcontroller were used for controlling the system, but in the present work an open source electronics platform Arduino was used to interface between hardware and software. ATmega-328p serial microcontroller was configured as Arduino comfortable. RF transceiver was used in this system. Android phone \& microcontroller were connected via IEEE802.15 standard device (Bluetooth) and all sensors serial outputs were being monitored by it. Block diagram of proposed Arduino open source microcontroller based home security system has shown in Fig.1. This system contains three parts such as input, control and output. At first controller section waits to response from the android mobile by sending a pulse through Bluetooth device to open the door. In this system, a manual $4 \times 4$ keypad was used to unlock and lock the door. An ultrasonic sensor with servo motor was used to detect unauthorized person moving around the door. If someone tries to unlock the system, then the sensor will be activated. This pulse is received by controller and the controller section activates the devices such as GSM module, LCD display, camera, RF Transceiver and buzzer.

However, making activation of output devices depends on the sensing pulses of the microcontroller from input section. To unlock or lock a home in legal way, signal is given to the Arduino via manual keyboard or android phone and the microcontroller sends a signal to the magnetic switch to lock or unlock the system. At same time message is displayed in LCD. When anyone tries to unlock the system in illegal way, ultrasonic sensor detects it with the help of microcontroller, camera will turn ON for taking picture or videos, GSM [19] module will send message to the owner of this system, RF transceiver will play buzzer at the long distance from the home because of being wireless device. Those activities can be easily informed to security guard and owner of home. Surrounding LED display placed at the home can indicate all wrong activities of this system. 
Inside the home a PIR sensor detects intrusion people and also alerts the owner of the system by displaying LCD and by sending SMS [20] with exact position through GSM module. This system is so called as multi operation security system. There is also a manual reset switch to regain this system in normal condition. This system contains two parts, one is hardware unit and another is system designing unit. At system designing unit, program has been designed with Arduino open source programmer flowing to the block diagram of this system.

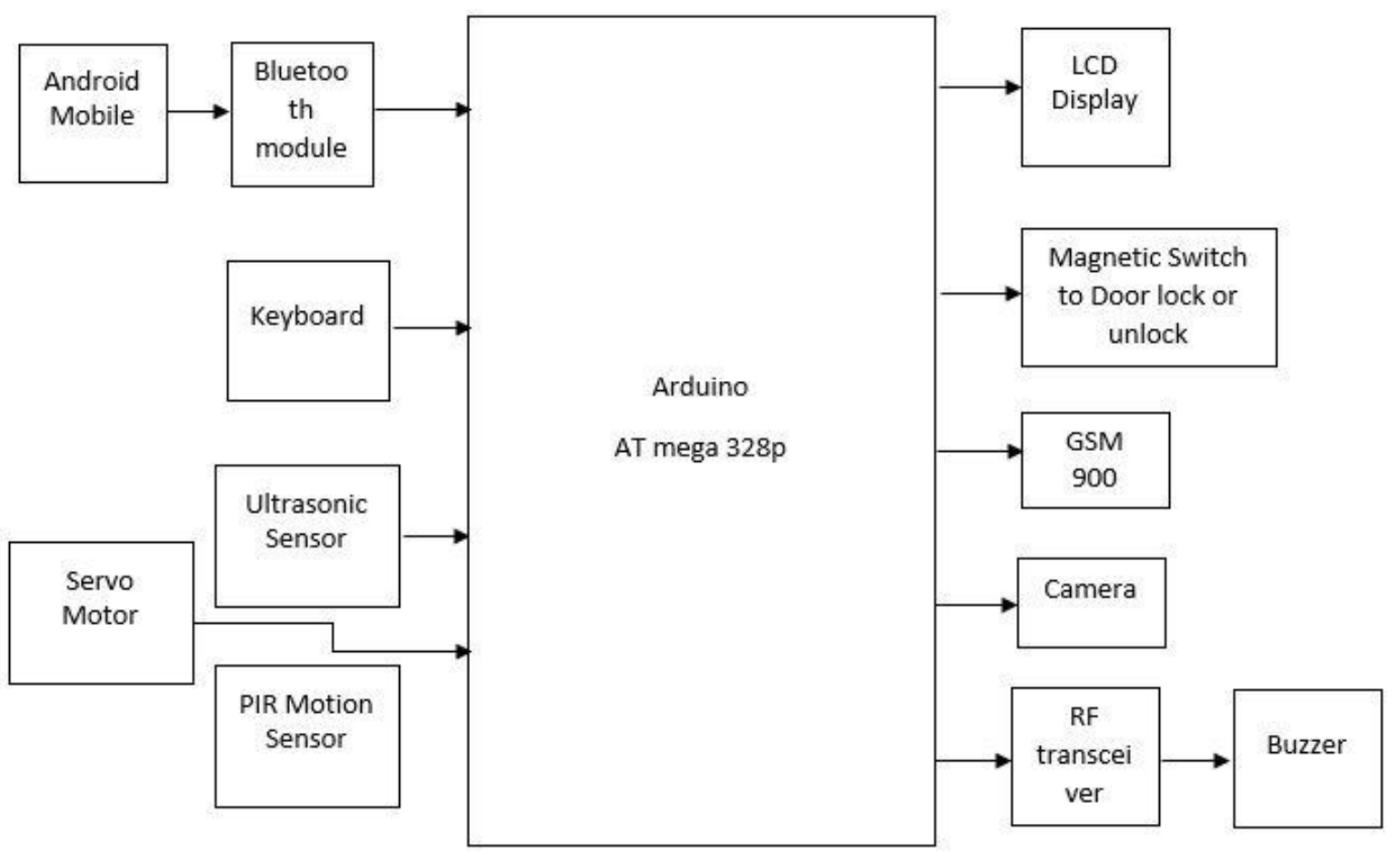

Fig.1. Block Diagram of Proposed Arduino Uno Open Source Microcontroller Based Home Security System.

\section{System Designing}

The flowchart of proposed home security system at password verification has shown in Fig.2 that indicates the procedure of software unit design. In the first flowchart the Bluetooth GSM module, RF transceiver and keypad are used. From where the microcontroller takes the input signal and after processing this signal, the microcontroller gives a signal to the corresponding devices. The microcontroller takes decision after getting input signal. Here gives a condition to verify door unlock, turn on the buzzer via RF transceiver. The second flowchart shows the camera swathing and SMS alert when proper signal is received by the microcontroller (Fig.3). 


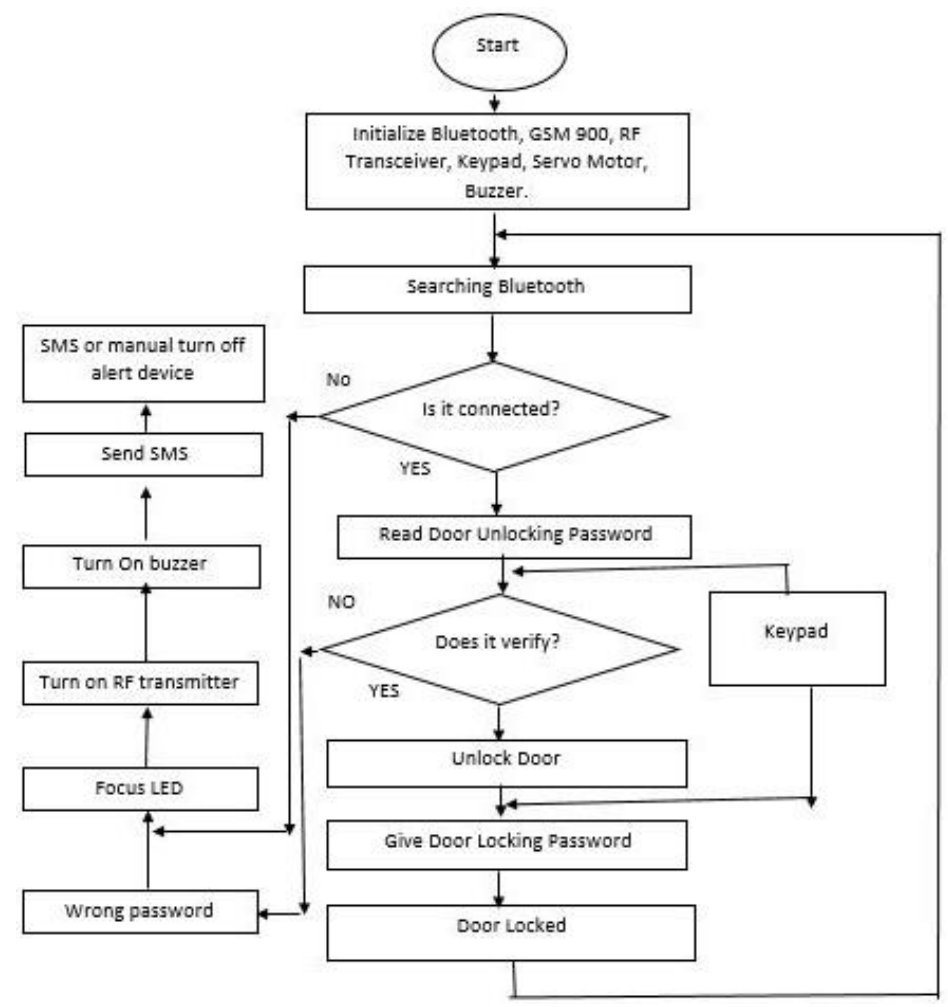

Fig.2. Flowchart of Proposed Home Security System at Password Verification.

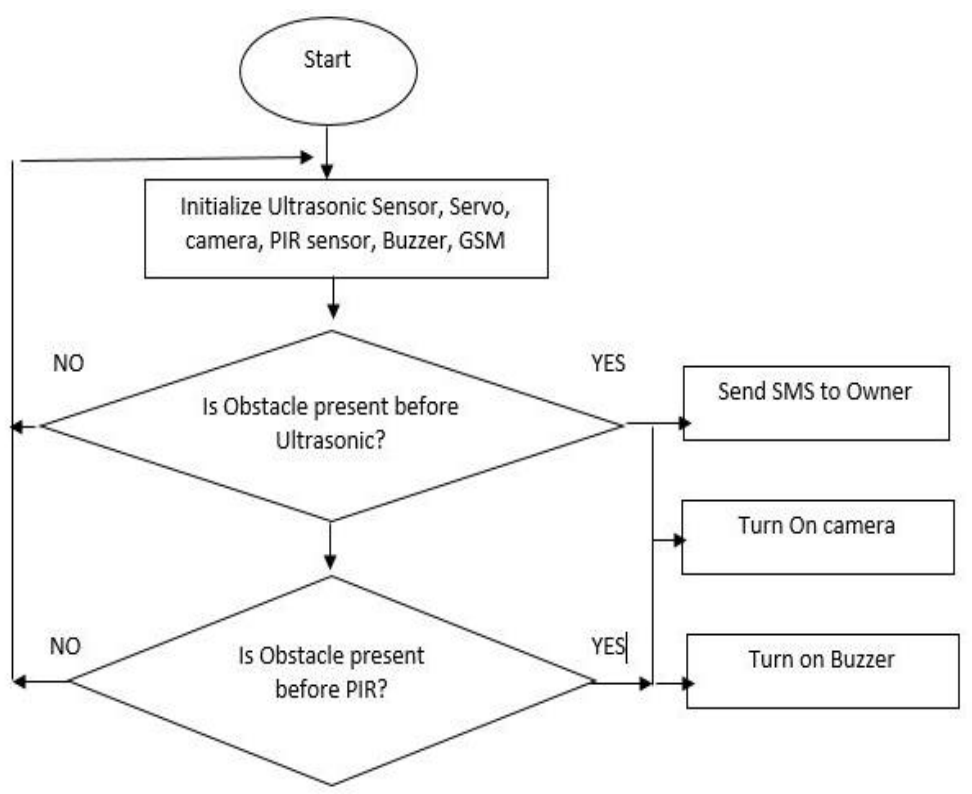

Fig.3. Flowchart of Proposed Home Security System by Obstacle Detection. 


\section{Hardware}

Intelligence based home security system was designed by using different types of sensing devices such as GSM 900 modules, LCD display, $4 * 4$ keypad, Servo motor, Ultrasonic sensor, PIR motion sensor, Camera [21] and buzzers etc.

GSM 900 module is a Quad-band cell phone comfortable with GSM technology. It works on $850 / 900 / 1800 / 1900 \mathrm{MHz}$ frequency. It is not used only for accessing internet but also communication for calling and SMS system. The GSM 900 module is shown in Fig.4.

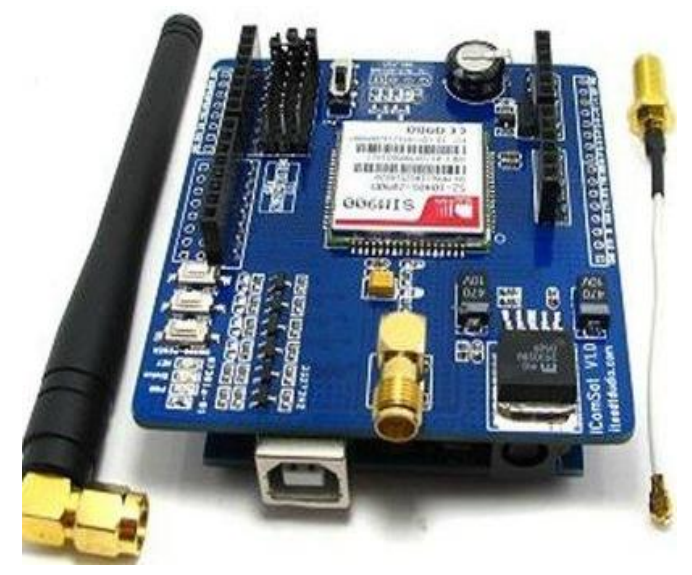

Fig.4. GSM 900 Module for Arduino.

LCD Display is an electronics visual display based on light modulating properties of liquid crystal.4*4 keypad consists of 16 individual characters. Each button gave an individual signal to identify each character. This LCD module is shown in Fig.5.

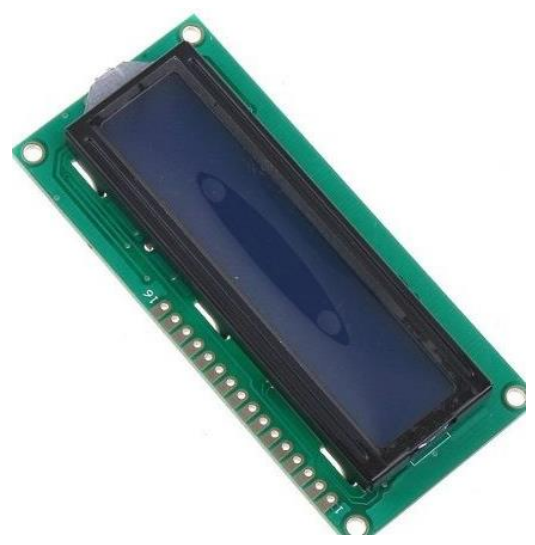

Fig.5. LCD 16*2.

Servo motor is nothing but a simple electrical motor with some gear that is controlled by giving pulse for a specific duration. Different sizes of gear help to control it to its desired position. The Fig.6 shows the Servo motor. 


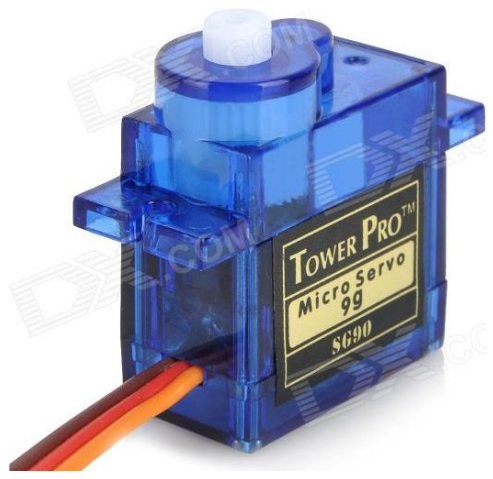

Fig.6. Servo sg90 Motor.

Ultrasonic sensor is a distance measurement device that sends trigger signal and receives eco signal from obstacle in front of it. Ultrasonic module is shown in Fig.7.

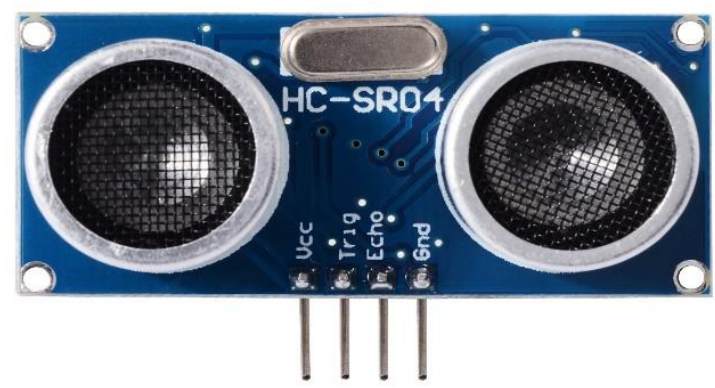

Fig.7. Ultrasonic Sensor.

PIR motion sensor is a device that detects the motion of human and other animal by using IR and Lens. This motion sensor is represented on Fig.8.

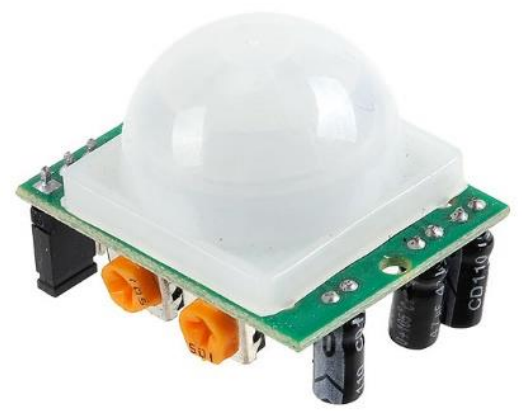

Fig.8. PIR Motion Sensor.

Bluetooth [22] is a device that creates a personal area wireless network in a short distance. It uses ISM band. The technological name of Bluetooth is IEEE 802.15 standard. A HC-05 number Bluetooth is shown in Fig.9. 


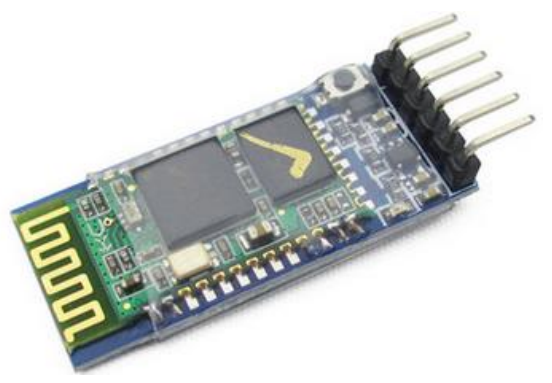

Fig.9. Bluetooth module HC-05.

RF transceiver $[23,24]$ is a wireless transmitter and receiver that uses radio frequency to communication. The radio frequency module is shown in Fig. 10.

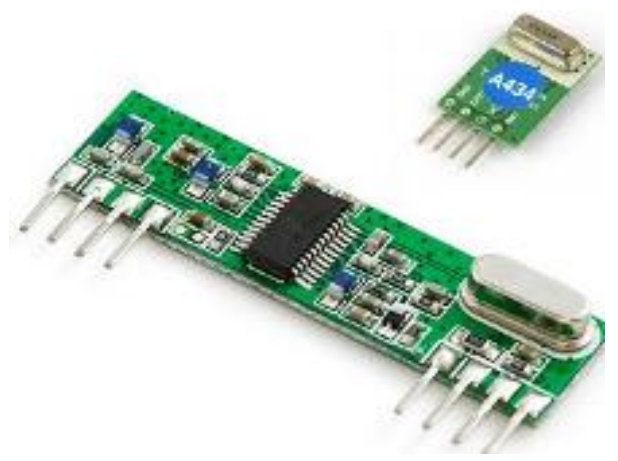

Fig.10. RF Transceiver.

Camera is a device that captures image and stores on this memory and it is also able to video. There are different types of camera. Each camera has different properties. Some camera's image quality is very good which depends on its pixel. A very useful pen camera with 32GB memory is shown in Fig.11.

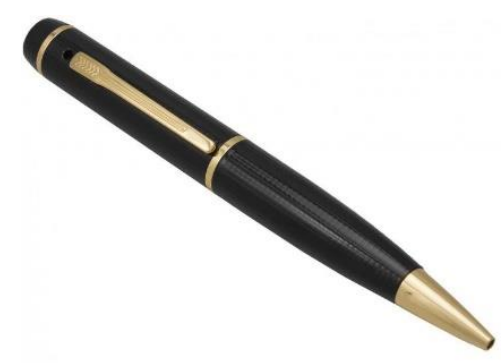

Fig.11. Pen Camera.

Keypad is an input device by which input is given to the microcontroller. There are different types of keypad. In this paper the $4 * 4$ keypad is used. The keypad's button gives the corresponding signal of this button present on that row and column. This keypad is shown in Fig.12. 


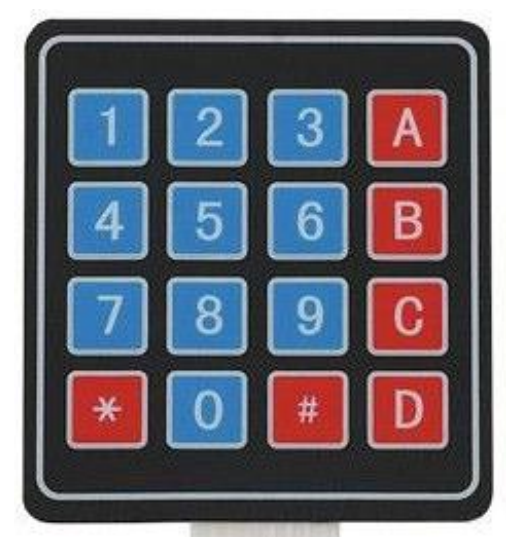

Fig.12. $4 * 4$ Keypad.

Buzzer is a sound generator device that produces sound very sharply. Buzzer is shown in Fig.13.

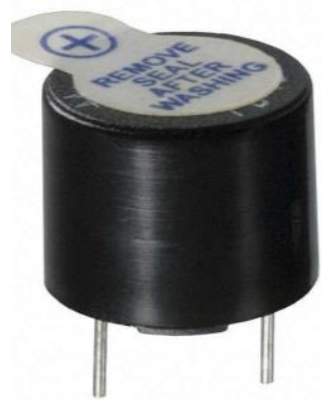

Fig.13. Buzzer.

The heart of this system was a microcontroller. Here Arduino Uno microcontroller was used. The microcontroller takes input signal and decides according to its given instruction. The Fig.14 shows the microcontroller of Arduino Uno configuration. Arduino is an open source platform with lots of library. This board holds ATmega328 microcontroller. To use the Arduino platform, the microcontroller, is to be configured as that configuration then it works on this platform.

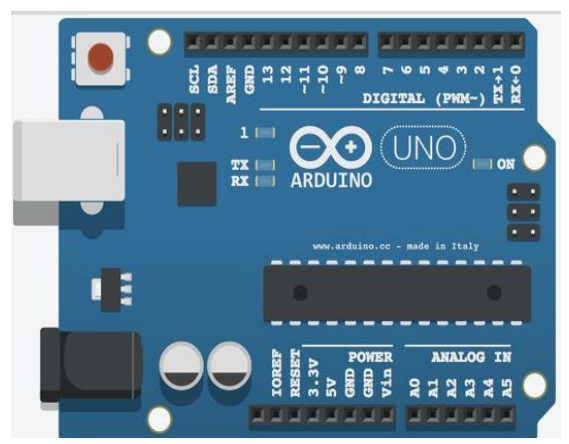

Fig.14. Arduino Uno. 
This system is designed by proteus simulation software with adding different types of library. This simulation circuit works properly. Implementation of this system is shown in Fig.15.

\section{Software Simulation Circuit}

After completing the system design and hardware selection schematic circuit is drawn in proteus simulation. The proteus simulation circuit works properly. When this circuit's all element and parts work accurately then this circuit is implemented that is shown in Fig.15.

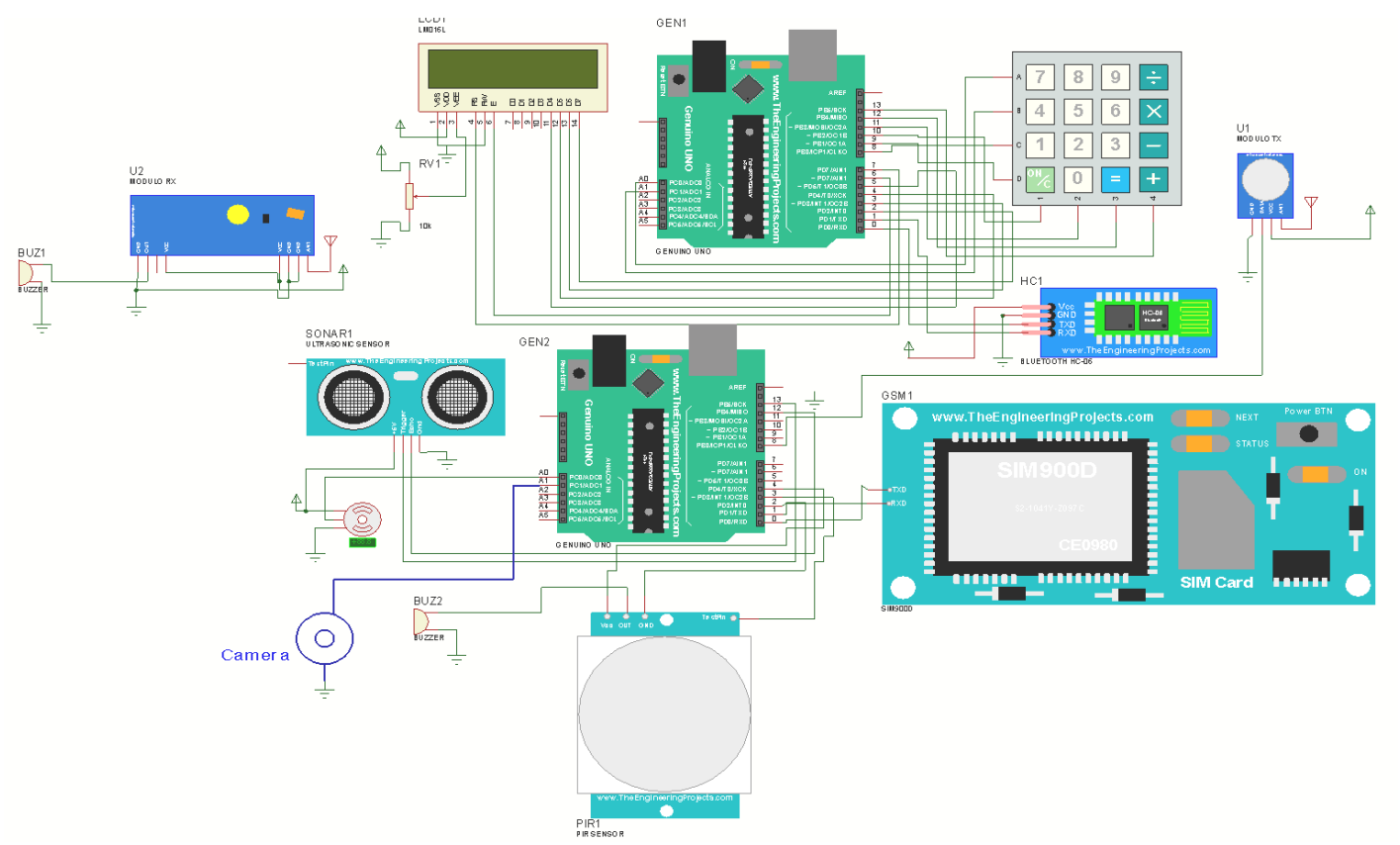

Fig.15. Schematic Diagram of the Proposed Home Security System

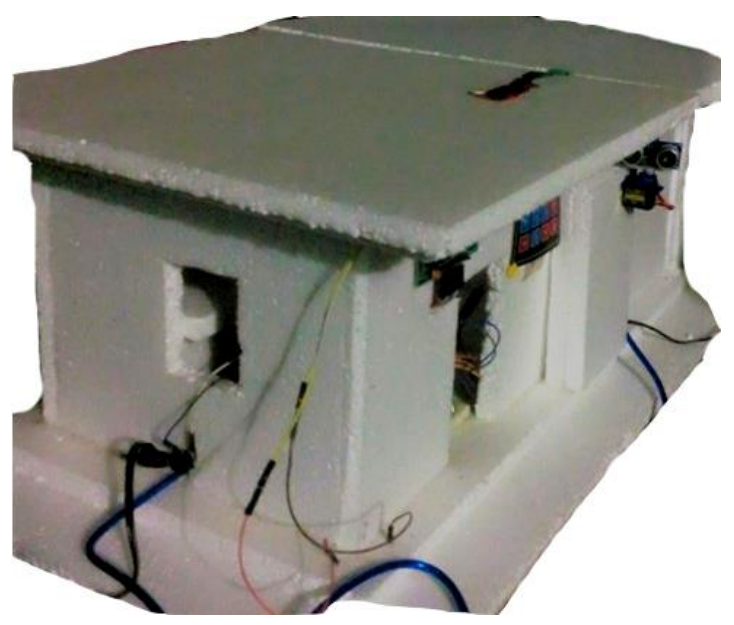

Fig.16. Implemented Circuit 


\section{Result and Discussion}

The implemented system is shown in Fig.16. All the sensors in this system were seen to perform accurately. PIR motion sensor detects any animal or human in motion very accurately and gives a desired output from this sensor. Gas detector detects gas around it and gives output properly. Bluetooth module generates responses with android phone very quickly. GSM 900 module was working properly and responded fast by sending and receiving SMS. The whole system's power supply was designed precisely that all the sensor and microcontroller get accurate power. No loading effect takes place on this system. To make the system more reliable, in this work, a camera has been added that capture video of surrounding areas [25]. GSM module makes it more secured because it updates information to the house owner through SMS. All units of the system work properly and provide services as a professional security guard. This system can be improved by adding Wi-Fi network [26] as it coverage area is larger than Bluetooth devices and through Wi-Fi network the video signal can be transmitted. There is also an option to capture image and send to the owner of the home. If more sensor or more functions are added, then the system will be highly secured.

To complete this complex home security system many problems had been faced. GSM 900 Arduino based module, RF Transceiver, Bluetooth interfacing with android application, PIR motion Sensor \& servo rotation were troublesome to ensure proper communication unitedly. Firstly, the power section of GSM module did not match. Another problem occurred for not having proper internal operating delay to complete its operation. However, all shortcomings and mismatches were resolved with utmost care and finally the system was seen to perform very well giving security and comfort with an intelligent way.

\section{Conclusions}

Home security system plays a vital role in daily life of city dwellers. It makes life easy, comfortable and free from worry. In the present research, an Arduino microcontroller based home security system was designed incorporating GSM module and many types of sensors. The system was made robust including several layers of security devices. If one of them fails or become unable to provide its function, another device will still be active ensuring complete security.

\section{References}

[1] Wong EM. A phone-based remote controller for home and office automation. IEEE Transactions on Consumer Electronics. 1994 Feb;40(1):28-34.

[2] Das CK, Sanaullah M, Sarower HM, Hassan MM. Development of a cell phone based remote control system: an effective switching system for controlling home and office appliances. International Journal of Electrical \& Computer Sciences IJECS. 2009 Dec;9(10):37-43.

[3] Azid SI, Kumar S. Analysis and performance of a low cost sms based home security system. International Journal of Smart Home. 2011 Jul;5(3):15-24.

[4] Gayathri M, Selvakumari P, Brindha R. Fingerprint and GSM based Security System. International Journal of Engineering Sciences \& Research Technology.;1(3):4024-7.

[5] S.Sujatha, M.Mohamed Irfan, B.Rhaagul "GSM Based Home Security System Using PLC" International Journal of Advanced Research in Electrical, Electronics and Instrumentation Engineering, Volume 5, Special Issue 1, March 2016.

[6] Bangali J, Shaligram A. Design and Implementation of Security Systems for Smart Home based on GSM technology. International Journal of Smart Home. 2013;7(6):201-8.

[7] Hasan R, Khan MM, Ashek A, Rumpa IJ. Microcontroller Based Home Security System with GSM Technology. Open Journal of Safety Science and Technology. 2015;5(02): 55.

[8] Shawki F, Dessouki ME, Elbasiouny AI, Almazroui AN, Albeladi FM. Microcontroller based smart 
home with security using GSM technology. IJRET: International Journal of Research in Engineering and Technology. 2015 Jun;4(06).

[9] Eseosa O, Promise E. GSM Based Intelligent Home Security System for Intrusion Detection. International Journal of Engineering and Technology. 2014 Oct;4(10):595-605.

[10] Budijono S, Andrianto J, Noor MA. Design and implementation of modular home security system with short messaging system. InEPJ Web of Conferences 2014 (Vol. 68, p. 00025). EDP Sciences.

[11] Agarwal N, Nayak SG. Microcontroller based home security system with remote monitoring. Special Issue of International Journal of Computer Applications. 2012:38-41.

[12] Hashim N, Razak MA, Idris F. HOME SECURITY SYSTEM USING ZIGBEE. Jurnal Teknologi. 2015 Jun 21;74(10).

[13] Bangare PS, Pote A, Bangare SL, Kurhekar P, Patil D. The Online Home Security System: Ways to Protect Home from Intruders \& Thefts. nternational Journal of Innovative Technology and Exploring Engineering (IJITEE) ISSN. 2013:2278-3075.

[14] Nandeesh GS, Srinivasalu Reddy B, Sunil Kumar KM. Intelligent Security System for Industries by using GPS and GSM. Int. J. Adv. Res. Comp. Sci. Technol. 2014;2(1):119-21.

[15] Md. Khalid Hossain, Mahbubul Hoq, Mohammod Abu Sayid Haque, Md. Shah Alam, Sarwar Hossen, M. Humayun Kabir, and Momtazul Islam, "Design and Development of a Low-cost Microcontroller Based Liquid Crystal Display (LCD) System for Electronic Instrumentation", Journal of Bangladesh Electronics Society, Vol. 15, No. 1-2, pp.33-38, 2015.

[16] Sarwar Hossen, M. K. Rahman, Md. Khalid Hossain, and Md. Khalid Hossain Jewel, "Design of a Microcontroller Based Electromagnetic Crane for Small Scale Applications", Journal of Bangladesh Electronics Society, Vol. 15, No. 1-2, pp.57-60, 2015.

[17] Md. Khalid Hossain Jewel, Md. Khalid Hossain, Rebeka Sultana, and Md. Shahadat Hossain, "Design and Development of a Low Cost Intelligent Home Appliances Automation System", Journal of Bangladesh Electronics Society, Vol. 15, No. 1-2, pp. 67-76, 2015.

[18] Md. Khalid Hossain Jewel, Md. Niaz Mostakim, A.S.M. shamim hasan, Md. Khalid Hossain, and Rebeka Sultana, "Design and Development of an Intelligent Obstacle Finder and Remover Vehicle on Predefined Street", Journal of Bangladesh Electronics Society, Vol. 15, No. 1-2, pp. 47-58, 2015.

[19] Ramani R, Valarmathy S, SuthanthiraVanitha N, Selvaraju S, Thiruppathi M, Thangam R. Vehicle tracking and locking system based on GSM and GPS. International Journal of Intelligent Systems and Applications. 2013 Aug 1;5(9):86.

[20] Shome S, Bera RN. SMS Tracking System with Doppler Radar to Enhance Car Security for Intelligent Transport System. International Journal of Intelligent Systems and Applications. 2015 Jan 1;7(2):50.

[21] Chaudhry N, Suleman KM. IP Camera Based Video Surveillance Using Object's Boundary Specification.

[22] Kaven Raj S/O Manoharan, Siew-Chin Chong, Kuok-Kwee Wee, "A Solution for Android Device Misplacement through Bluetooth-enabled Technology", International Journal of Intelligent Systems and Applications(IJISA), IJISA Vol. 7, No. 11, October 2015.

[23] Mohamed HA. A Proposed Model for Radio Frequency Systems to Tracking Trains via GPS (The Study for Egyptian National Railways). International Journal of Intelligent Systems and Applications. 2014 Mar $1 ; 6(4): 76$

[24] Robinson P. Paul, Ghansyam B. Rathod, Vishwa R. Trivedi, Punit V. Thakkar,” Persistence of Vision control using Arduino", International Journal of Intelligent Systems and Applications(IJISA), IJISA Vol. 6, No. 1, December 2013.

[25] Vineeth N, Guruprasad HS. Delay Analysis of Network Coded Video Streams in VANETs. International Journal of Information Engineering and Electronic Business. 2015 Jul 1;7(4): 16.

[26] Bhowmik B, Thakur N, Sarkar P. Experimental Analysis of Xie and Kuek's Traffic Model with Handoff Scheme in Wireless Networks. International Journal of Information Engineering and Electronic Business. 2012 Feb 1;4(1): 34. 


\section{Author's Profiles}

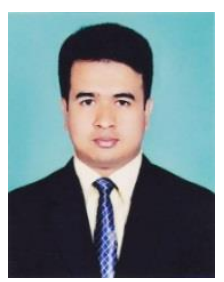

Md. Khalid Hossain Jewel received his Bachelor's and Master's degree from the dept. of Applied Physics, Electronics \& Communication Engineering of Islamic University, Kushtia7003, Bangladesh in 2004 and 2005 respectively. In 2015 he completed his M.Phil degree in wireless communication. Currently he is working as an assistant professor in the same department. His research interest includes Ad-hoc wireless communication, cellular mobile communication and optical fiber communication.

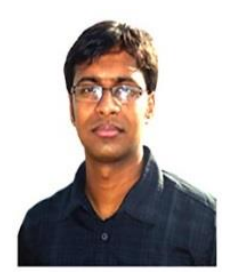

Md. Niaz Mostakim received his B.Sc. (Hons') degree from the dept. of Applied Physics, Electronics and Communication Engineering of Islamic University, Kushtia-7003, Bangladesh in 2013. Currently he is a M.Sc. final year student in the same department. His current interest includes microcontroller based system design, electronics system design and development, MATLAB based system development, MATLAB programming interface with microcontroller and communication engineering. He received University Merit Scholarship for his outstanding B.Sc. (Hons') $1^{\text {st }}$ class $1^{\text {st }}$ merit position out of 40 successful students from the authority of Islamic University, Bangladesh.

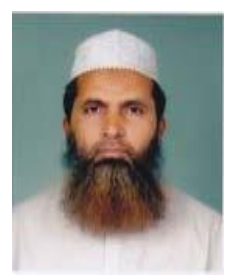

M. K. Rahman was born on July 1, 1971 in Madaripur, Bangladesh. He received the M.Sc. degree in Applied Physics, Electronics \& Communication Engineering from University of Dhaka, Bangladesh in 1992. He is currently a Professor in the Department of Applied Physics, Electronics \& Communication Engineering, Faculty of Applied Science \& Technology, Islamic University, Kushtia-7003, Bangladesh. His interest is in Optoelectronics and Wireless Communication. His work has produced nearly 20 National and International papers.

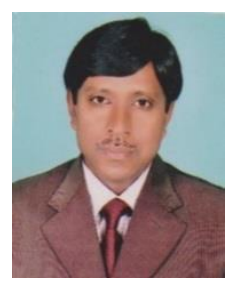

Dr. Md. Shahjahan Ali received his B.Sc (Hons) and M.Sc in 1988 1nd 1989 respectively in Applied Physics and Electronics from Rajshahi University, Bangladesh. He received Ph.D in engineering and technology from Dhaka University in 2011. He is currently a Professor in the Department of Applied Physics, Electronics \& Communication Engineering, Faculty of Applied Science \& Technology, Islamic University, Kushtia-7003, Bangladesh. His research interest includes modelling and optimization of wireless network and application of remote sensing technology.

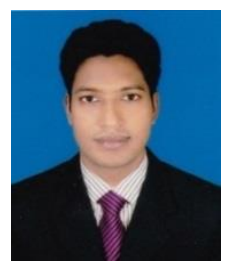

Sheikh Dobir Hossain is working as a Assistant Professor in the dept. of Physics at Jessore University of Science and Technology, Jessore-7408, Bangladesh. He holds the degree of B.Sc \& M.Sc in Applied Physics, Electronics \& Communication Engineering from Islamic University, Kushtia-7003, Bangladesh. The fields of his research interest are wireless antenna design, wireless communication, and material science. 


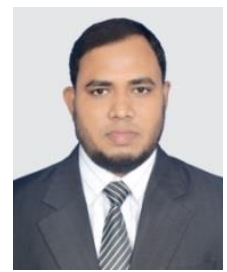

Md. Khalid Hossain has been received the B.Sc. (Hons) and M.Sc. degree in Applied Physics, Electronics \& Communication Engineering of Islamic University, Kushtia-7003, Bangladesh in 2008 and 2009 respectively. Currently he is working as a Scientific Officer in the Institute of Electronics, Atomic Energy Research Establishment (AERE), Bangladesh Atomic Energy Commission (BAEC), Savar, Dhaka-1349, Bangladesh. His current interests are advanced materials science, functional materials, photovoltaic devices, thin film, Micro/Nano fabrication, biosensor, intelligent systems design etc. He is the author/co-author of more than 20 international papers.

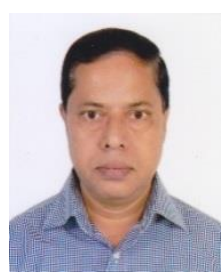

Himangshu Kumar Ghosh has been received the B.Sc. (Hons) and M.Sc. degree in Applied Physics \& Electronics from University of Rajshahi, Rajshahi-6205, Bangladesh in 1985 and 1986 respectively. Currently, he is working as Chief Scientific Officer and Director at the Institute of Electronics, Atomic Energy Research Establishment (AERE), Bangladesh Atomic Energy Commission (BAEC), Savar, Dhaka-1349, Bangladesh. His current research interests are nuclear instrumentation, radiation effects on semiconductor \& electronic devices, solar cell, intelligent systems design etc.

How to cite this paper: Md. Khalid Hossain Jewel, Md. Niaz Mostakim, M. K. Rahman, Md. Shahjahan Ali, Sheikh Dobir Hossain, Md. Khalid Hossain, Himangshu Kumar Ghosh,"Design and Development of a Versatile and Intelligent Home Security System", International Journal of Engineering and Manufacturing(IJEM), Vol.7, No.4, pp.60-72, 2017.DOI: 10.5815/ijem.2017.04.06 